\title{
Inoue balloon rupture during dilatation of calcified mitral valves
}

\author{
Richard J Schilling, C M Francis, T R D Shaw, Michael S Norell
}

The Inoue balloon is a popular device for percutaneous dilatation of the mitral valve. ${ }^{1-3}$ The balloon consists of two layers of latex between which is a lattice of strands of semisynthetic fibre which gives the balloon its

Department of
Cardiology, Hull
Royal Infirmary,
Kingston-upon-Hull
R J Schilling
M S Norell
Department of
Cardiology, Western
General Hospital,
Edinburgh
C M Francis
T R D Shaw
Correspondence to:
Dr R J Schilling, Hull Royal
Infirmary, Anlaby Road,
Hull HU3 2JZ.

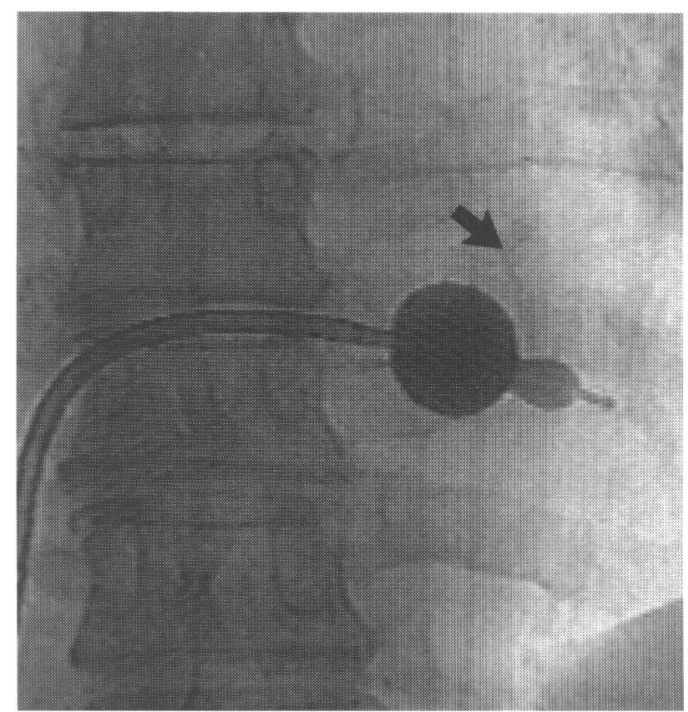

Figure 1 Fluoroscopy showing abnormally inflated balloon and mitral valve calcification (arrow).
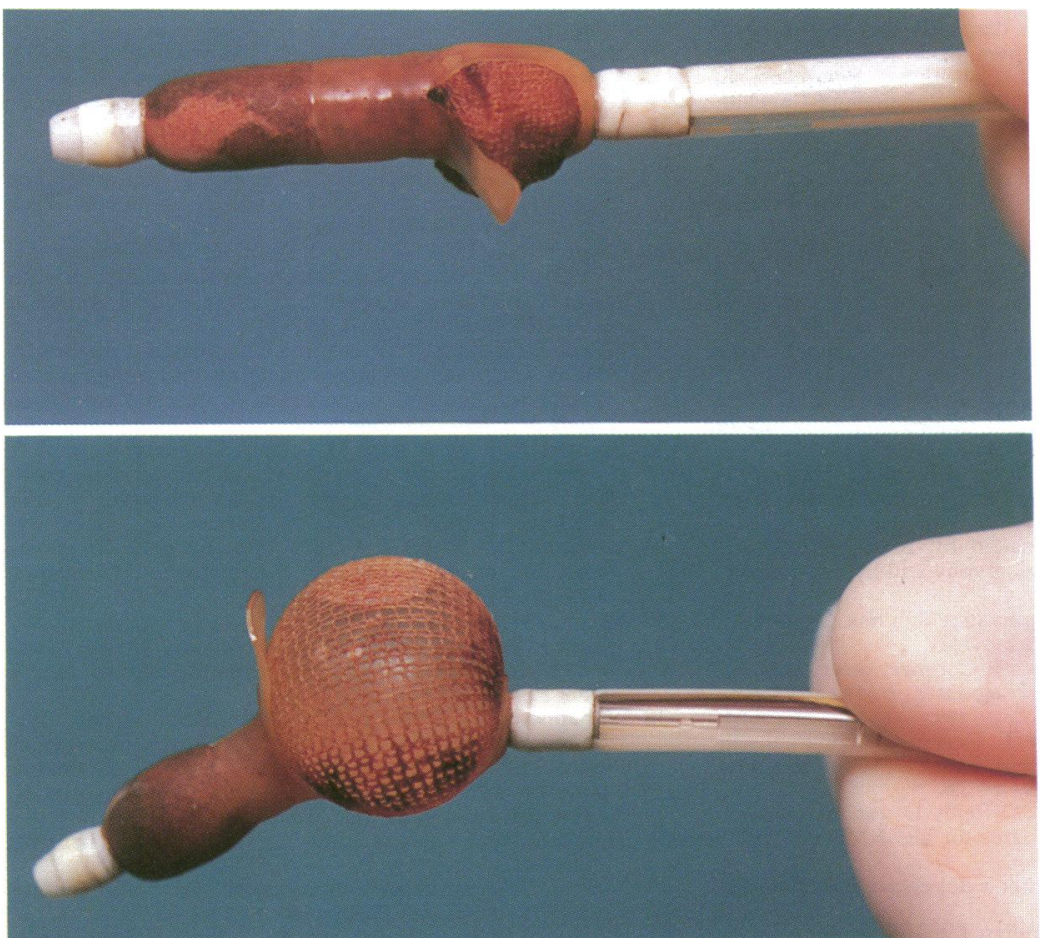

Figure 2 Photograph showing tear in outer rubber layer and herniation of semisynthetic mesh on inflation. special compliance characteristics. ${ }^{12}$ The distal portion inflates first, allowing it to be pulled back to abut the mitral orifice. The proximal portion then expands helping to keep the balloon in position on the valve orifice.

Two patients underwent percutaneous dilatation of the mitral valve. Both patients had calcification of the mitral valve (fig 1 , arrow). The proximal portion of the balloon was seen to inflate first during the final balloon inflation in the first patient and twice in the second patient. This caused the balloon to be ejected back into the atrium. Inspection of the balloons showed that the outer layer had torn (fig 2).

The design of the Inoue balloon allows much shorter screening times, ${ }^{4-6}$ partly as a result of its special compliance characteristics. The two cases described suggest that if the outer rubber layer impinges on valve calcification it can tear. In the second case both balloons tore after inflation to full size, suggesting that this was not due to an intrinsic weakness in the rubber. Chow et al also reported two cases in which the proximal portion of the balloon tore but did not say whether the valves were calcified. ${ }^{7}$

Though the three layer wall of the Inoue balloon may be apt to tear, it prevents release of the balloon contents into the circulation, whereas cylindrical polyethylene balloons do not. ${ }^{8}$

1 Inoue K, Owaki T, Nakamura T, Kitamura F, Miyamoto N. Clinical application of transvenous mitral commissurotomy by a new balloon catheter. $\mathcal{F}$ Thorac Cardiovasc Surg 1984;87:394-402.

2 Inoue K, Fledman T. Percutaneous transvenous commissurotomy using the Inoue balloon catheter. Cathet Cardiovasc Diagn 1993;28:199-225.

3 Wilkins GT, Weyman AE, Abascal VM, Block PC, Palacios IF. Percutaneous dilatation of the mitral valve an analysis of echocardiography variables related to outcome and the mechanism of dilatation. Br Heart $f$ 1988;60:299-308.

4 Chen CR, Huang ZD, Lo ZX, Cheng TO. Comparison of single rubber-nylon balloon and double polyethylene salle rulvulo val in 94 patients with rheumatic mitral stenosis. Am Heart f 1990;199:102-11.

5 Abdullah M, Halim M, Rajendran V, Sawyer W, al Zibag $M$. Comparison of single (Inoue) and double balloon $M$. Comparison of single (Inoue) and double balloon valvuloplasty: immed

6 Ribeiro PA, Fawsy ME, Arafar MA, Dunn B, Sriram R, Mercer E, Duran CA. Comparison of mitral valve areas, Mercer E, Duran CA. Comparison of mitral valve areas, results of balloon mitral valvotomy using Inoue and
double balloon techniques. Am $\mathcal{f}$ Cardiol 1991;68: double

7 Chow WH, Chow TC, Cheung KL. Angiographic recognition of a proximal balloon tear during Inoue balloon mitral valvotomy. Cathet Cardiovasc Diagn 1993;28 235-7.

8 Bassand JP, Schiele F, Bernard Y, Daspet JP, Maurat JP. The double balloon and Inoue techniques in percutaneous mitral valvuloplasty. $\mathcal{f}$ Am Coll Cardiol 1991;19: 982-9. 